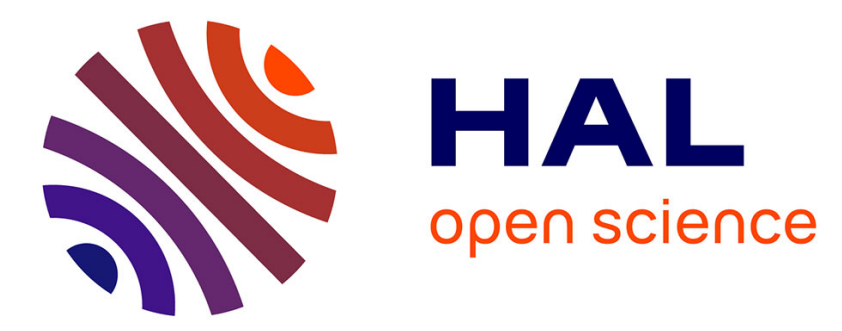

\title{
Preliminary assessment of ship detection and trajectory evaluation using distributed acoustic sensing on an optical fiber telecom cable
}

Diane Rivet, Benoit de Cacqueray, Anthony Sladen, Aurélien Roques, Gaëtan Calbris

\section{To cite this version:}

Diane Rivet, Benoit de Cacqueray, Anthony Sladen, Aurélien Roques, Gaëtan Calbris. Preliminary assessment of ship detection and trajectory evaluation using distributed acoustic sensing on an optical fiber telecom cable. Journal of the Acoustical Society of America, 2021, 149 (4), pp.2615-2627. 10.1121/10.0004129. hal-03209679

\section{HAL Id: hal-03209679 \\ https://hal.science/hal-03209679}

Submitted on 10 Dec 2021

HAL is a multi-disciplinary open access archive for the deposit and dissemination of scientific research documents, whether they are published or not. The documents may come from teaching and research institutions in France or abroad, or from public or private research centers.
L'archive ouverte pluridisciplinaire HAL, est destinée au dépôt et à la diffusion de documents scientifiques de niveau recherche, publiés ou non, émanant des établissements d'enseignement et de recherche français ou étrangers, des laboratoires publics ou privés. 
Preliminary assessment of ship detection and trajectory evaluation using distributed acoustic sensing on an optical fiber telecom cable

Running title : Ships Tracking on Distributed Acoustic Sensing

To be submitted to The Journal of the Acoustical Society of America

Diane Rivet ${ }^{1 *}$, Benoit de Cacqueray $^{2}$, Anthony Sladen ${ }^{1}$, Yves Doisy ${ }^{2}$, Aurélien Roques ${ }^{2}$, Gaëtan Calbris ${ }^{3}$

${ }^{1}$ Université de la Côte d'Azur, Observatoire de la Côte d'Azur, CNRS, IRD, Géoazur 250 route d'Albert Einstein, 06220 Valbonne, France

2 Thales Defense Mission System, 525 Route des Dolines, 06560 Valbonne

${ }^{3}$ FEBUS-optics, Technopole Helioparc - 2 av. Président Pierre Angot - 64000 Pau - France

* Corresponding author: Diane Rivet, diane.rivet@geoazur.unice.fr 


\section{Abstract}

We detect maritime vessels on a $41.5 \mathrm{~km}$ long fiber optic telecom cable using distributed acoustic sensing. We measure noise emitted by the same tanker cruising one day at a distance of $5.7 \mathrm{~km}$ from the shore, above $85 \mathrm{~m}$ of water, and the following day at a distance of $20 \mathrm{~km}$ from the shore, above $2000 \mathrm{~m}$ of water. The acoustic emissions of the tanker result in measurable strain rate on the optical fiber cable laid on the seafloor and probably, for some sections, covered by sediments. The spectral signature of the engines of the ships, the doppler effect, and the apparent velocity of the acoustic waves on the fiber allow to separate the ship noise from the environmental and the DAS interrogator noises. The broad band sensitivity of the distributed acoustic sensing allows to identify tanker acoustic noise at frequencies ranging from 16 to $100 \mathrm{~Hz}$ on the noise content measured up to $1 \mathrm{kHz}$. At $85 \mathrm{~m}$ water depth, the signal to noise ratio is high, and the trajectory of the boat is recovered from beam forming analysis of the distributed strain rate measured every $6.4 \mathrm{~m}$. At this shallow depth it is possible to track the position of the tanker up to $2 \mathrm{~km}$ away from the cable. The main features of the intensity of the acoustic noise in space and time is well model using a ray-based model of the acoustic wave propagation in the sea and converted into longitudinal strain rate, as it is seen by the cable. On the open sea, at $2000 \mathrm{~m}$ water depth, the acoustic signal of the ship is more attenuated, however narrow bands signals below $50 \mathrm{~Hz}$ are still detected by the DAS. In both route of the cruising tanker, we assess the possibly to use the Doppler shift of the emitted frequency to estimate the tanker velocity. These results confirm the high potential of DAS technology using telecom cable for a remote and quantitative monitoring of the maritime traffic and for vessel tracking on shallow water but also at great depth. 


\section{Introduction}

Ambient noise in the ocean results from natural and anthropogenic sources. This anthropogenic noise produced by maritime traffic has dramatically increased with the development of industrialization and global trading. Over the last decade, the scientific community has shown that acoustic noises strongly impact all marine lives, from mammals to zooplankton, including fish, sea turtles and invertebrates (e.g. Whilliams et al. 2015). For example, marine mammals use sound for different important activities like finding food, detecting predator, breeding and navigation. Awareness soon grew in the community of a need to limit man-made underwater noise. To limit the ricks to marine ecosystems, International policy imposes new legislations at the regional and international scales (Merchant 2019). To better evaluate environmental and anthropic noises and their impacts on marine species, continuous measures of the noise, both on the coast and off shore need to be done.

Another important aspect of underwater ambient noise monitoring is the detection and the tracking of maritime vessels. Maritime traffic has a great economic impact, as it represents $90 \%$ of global trades, but also encompasses important safety and security aspects of high priority for international institutions. Automatic Identification System (AIS) data provides the identity and position of vessel, however it is self-reporting and concerns only large vessel (Velpe et al. 2012). Independent monitoring and tracking of ships is therefore crucial for key infrastructures such as harbors, power plants. For instance, submarine telecom cables which are very sensitive for global communications, can be threat by anchors, seabed trawlers, and other type of activities (Rønnekleiv et al. 2019). Sonars cannot entirely fulfill at reasonable coast the mission of monitoring and tracking ships over tenth of kilometers.

Measuring continuously acoustic noise over long distance in the underwater environment requires costly and hard to maintain hydrophones and sonar. Distributed Acoustic Sensing 
(DAS) on existing seafloor optical cable provides a remote monitoring of the acoustic noise over several tenth of kilometer off shore at relatively low cost, but the feasibility of monitoring acoustic wave on all oceanic domains and bandwidths remains to be assessed.

Distributed acoustic sensing measures elastic and acoustic waves on optical fibers. This technology has a very high potential in many applications and in recent years there has been growing interest in earth and environmental sciences. DAS exploits changes in back scattering light produced by nano-metric elongations of the optical fiber when it is stretched or when waves pass through it. This scattering effect is called Rayleigh backscattering and a linear phase shift of the back-shattering light is associated to the longitudinal strain of the fiber. For the Optical Time Domain reflectometer (OTDR) technology, the strain or strainrate are thus measured from the difference of two phase changes over a distance called the gauge length. In seismology application, seismic waves are generally measured with a spatial resolution of about ten meters (e.g. Jousset el al. 2018, Ajo-Franklin et al. 2019).

DAS has proven its efficiently for monitoring sensitive infrastructures like pipelines, railways, dams, and it is becoming more and more used for seismic imaging and monitoring oil fields and wells (e.g. Mateeva et al. 2013, Miller et al. 2016). More recently applications in seismology used dedicated or not optical fiber cables on the ground floor (e.g. Dalley et al. 2013, Dou et al. 2017) sometimes through beamforming (Lindsey et al. 2017). Last year, the first DAS applications in underwater environment were performed in three different settings (Sladen et al. 2019, Lindsey et al. 2019, ), using existing telecom optical fiber. In addition to earthquake monitoring, environmental signals such as the gravity waves, microseismic noise are accurately measured with unprecedented details. However, the higher frequency content of has not been yet fully analyzed. At shallow water depth (30m) DAS has revealing his potential to monitor boat and trawlers (Rønnekleiv et al. 2019). Here we further explore the 
potential of such technology to detect and track vessels in deeper environment on a telecom cable.

\section{Method and instrumental setup}

The DAS acquisitions were made on a $41.5 \mathrm{~km}$-long electro-optic telecommunication cable from Alcatel deployed offshore Toulon in south of France. The MEUST- NUMerEnv project (Mediterranean Eurocentre for Underwater Sciences and Technologies - Neutrino Mer Environnement) is operating the cable and provide power and data transmission for numerous oceanographic studies in the framework of EMSO program and for the KM3NeT/ORCA (Oscillation Research with Cosmics in the Abyss) neutrino detector (Coyle et al. 2017). Crossing different oceanic domains of the Mediterranean margin, from the continental shelf to the abyssal plain, the cable simply laid on the seafloor reaches a depth of $2400 \mathrm{~m}$ on the abyssal plain (Figure 1). From $2.1 \mathrm{~km}$ up to $17.2 \mathrm{~km}$ off the coast, the cable is Single Armoring Heavy (SAH) then Light-Weight Protection (LWP) for the remaining $24 \mathrm{~km}$.

The DAS interrogator, provided by Febus Optics, was used from February 19th to February 24th, 2018. In this experiment, the gauge length was fixed to $19,4 \mathrm{~m}$, with a sampling every 6.4 meters. With a temporal sampling of $2 \mathrm{kHz}$, waves up to $1 \mathrm{kHz}$ can be theoretically accurately retrieve with no temporal aliasing. However, the chosen spatial sampling and gauge length only allow a non-aliased in space acoustic signal up to $114 \mathrm{~Hz}$.

Vessels cruising in the Mediterranean Sea reported their position to the Automatic Identification System (AIS) database. During the DAS acquisition, a 85m long Tanker passed over the FO cable on two different positions, first at $5.8 \mathrm{~km}$ off the shore with a $\mathrm{N} 260^{\circ}$ route at a velocity of $11 \mathrm{knot}$, and few days after, the same tanker passed over the cable at $20 \mathrm{~km}$ from the coast with a $\mathrm{N} 83^{\circ}$ route at a velocity of $7.8 \mathrm{knot}$, crossing the fiber with an angle of $71^{\circ}$ (Figure 1, red bars). 


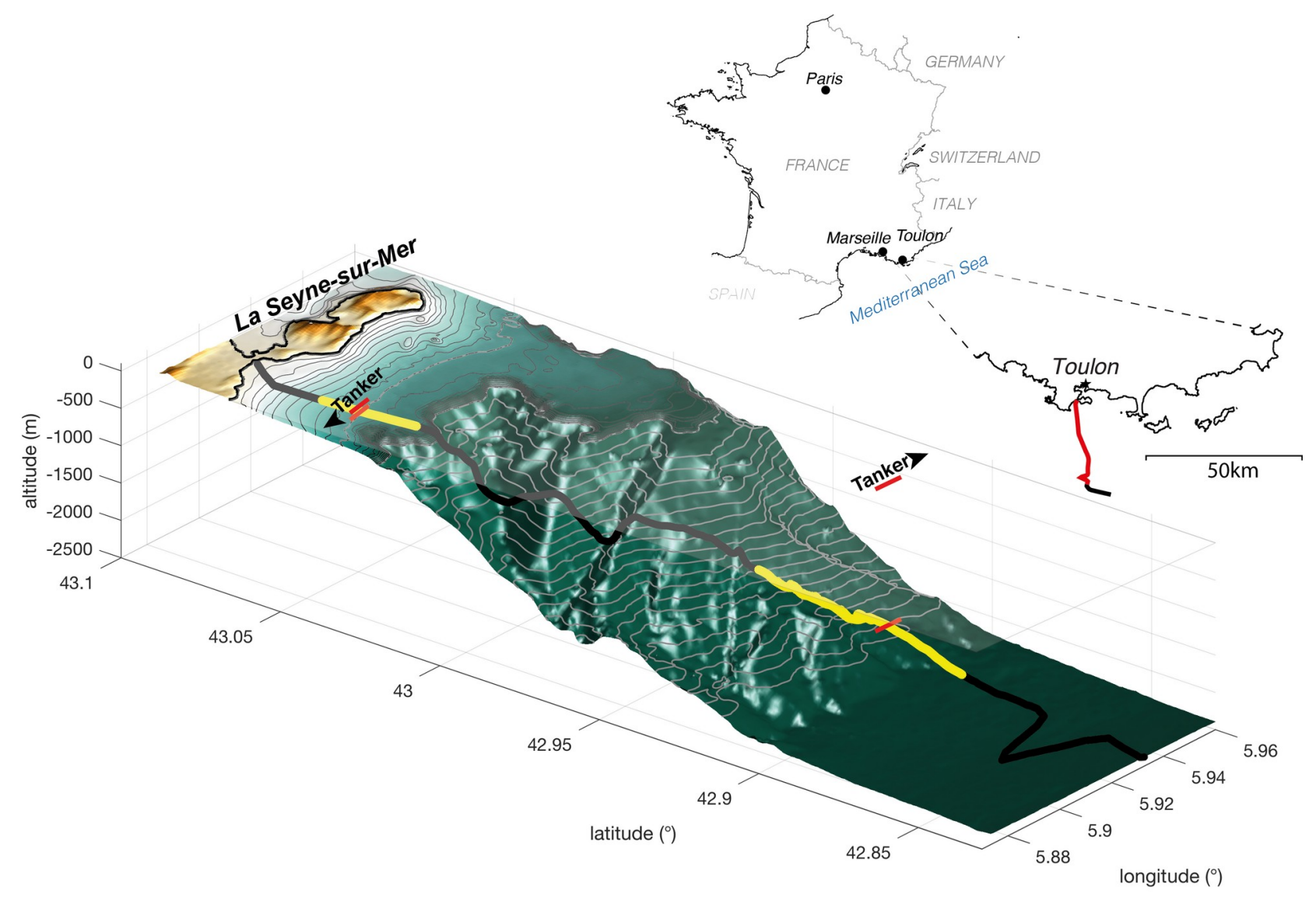

Figure 1 Location of the MEUST-Numerenv optical fiber offshore of La Seyne-sur-Mer located in the vicinity of Toulon, south of France. The $41.5 \mathrm{~km}$ cable lies on the continental shelf for the first 7.5 kilometers before reaching the steep continental slope. The first $35 \mathrm{~km}$ of the cable is indicated by the red section of the cable indicated in the map. The first route of the tanker at 5,8 $\mathrm{km}$ from the coast is known from the two AIS GPS positions at 13:07:08 and 13:09:23 and the second route of the tanker at $20 \mathrm{~km}$ from the coast is known from the AIS GPS positions at 09:15:34 and 19:18:14, Both routes are shown by the red thick line on the sea surface. The projection of the tanker routes crossing the cable at 5.8 and $20 \mathrm{~km}$ are indicated by the red lines on the sea floor. The two yellow sections of the cable indicate the portion of the fiber we used to detect the acoustic waves emitted by the ship.

\section{Maritime vessel detection}

Ship noise modeling is an already old (Gray and Greeley 1980) and complex (Fournier 2009) field that cannot be easily summarized. However, a constant feature of ship noise is a 
spectrum characterized by two main components (e.g. Pillon 2016). The first one is a wideband signal resulting from multiple sources like pumps, fans, fluid streams in the pipes or along the shell. This component is sometime considered having a Gaussian shape with a maximum at few dozen of Hertz. The second component is a sum of narrow band signals coming from rotating elements (mainly linked to propeller activity but not only) and electrical network (50 or $60 \mathrm{~Hz}$ ). The higher frequencies are also characterized by narrow band signals, often with a noise floor showing a decreasing slope of several $\mathrm{dB}$ per decade.

At $85 \mathrm{~m}$ depth, strain-rate records on the fiber show both features of ship noise: the Fourier transform of 8 minutes of signals coming from one DAS receiver shows a gaussian broad band noise and high amplitude narrow band signals (Figure 2c). These narrow bands signals, with high signal to noise ratio, appear in the strain-rate time-frequency diagram, as the boat is getting closer to the fiber (Figure 2a). At its dominant frequency, around $49 \mathrm{~Hz}$, the intensity of the noise reach $35 \mathrm{~dB} / \mathrm{Hz}$ on average during the 8 minutes of records (Figure 2c) and the signal is seen by the receiver during about 5 minutes (Figure 2a). Considering the mean ship velocity given by the AIS system during this period (about 11 knots) and his route (almost perpendicularly from the fiber), it means that the $49 \mathrm{~Hz}$ signal from the ship is recorded over about $1700 \mathrm{~m}$. If the displacement is roughly symmetrical, it means that the signal start to be recorded about $850 \mathrm{~m}$ away from the fiber, when the boat travel roughly perpendicular to the fiber (Figure 4a). On the strain rate time series the noise level increases by a factor of two for one minute (Figure $2 b$ ).

At $2000 \mathrm{~m}$ depth, acoustic noise emitted from the boat are more attenuated and the signal to noise ratio is lower (Figure 3). Any significant increase of the amplitude of strain-rate time series is observed when the tanker passes over the cable. Still, we identify high energy narrow bands of the same frequency as those seen at shallow depth. At its dominant frequency, $49 \mathrm{~Hz}$, the intensity of the noise reach $26 \mathrm{~dB} / \mathrm{Hz}$ on average during the 9 minutes of 
records (Figure 3c). Other peaks around $57 \mathrm{~Hz}$ is still visible. However, peaks around $16 \mathrm{~Hz}$, $33 \mathrm{~Hz}, 41 \mathrm{~Hz}, 76 \mathrm{~Hz}$ and $83 \mathrm{~Hz}$ that can be observed the first day are replaced by peaks around $21 \mathrm{~Hz}$ and $29 \mathrm{~Hz}$. The tanker speed variations can be responsible for some changes in the emitted frequencies, as well as the greater attenuation of the acoustic waves due to the $2000 \mathrm{~m}$ water column affect the amplitude of the high frequencies.

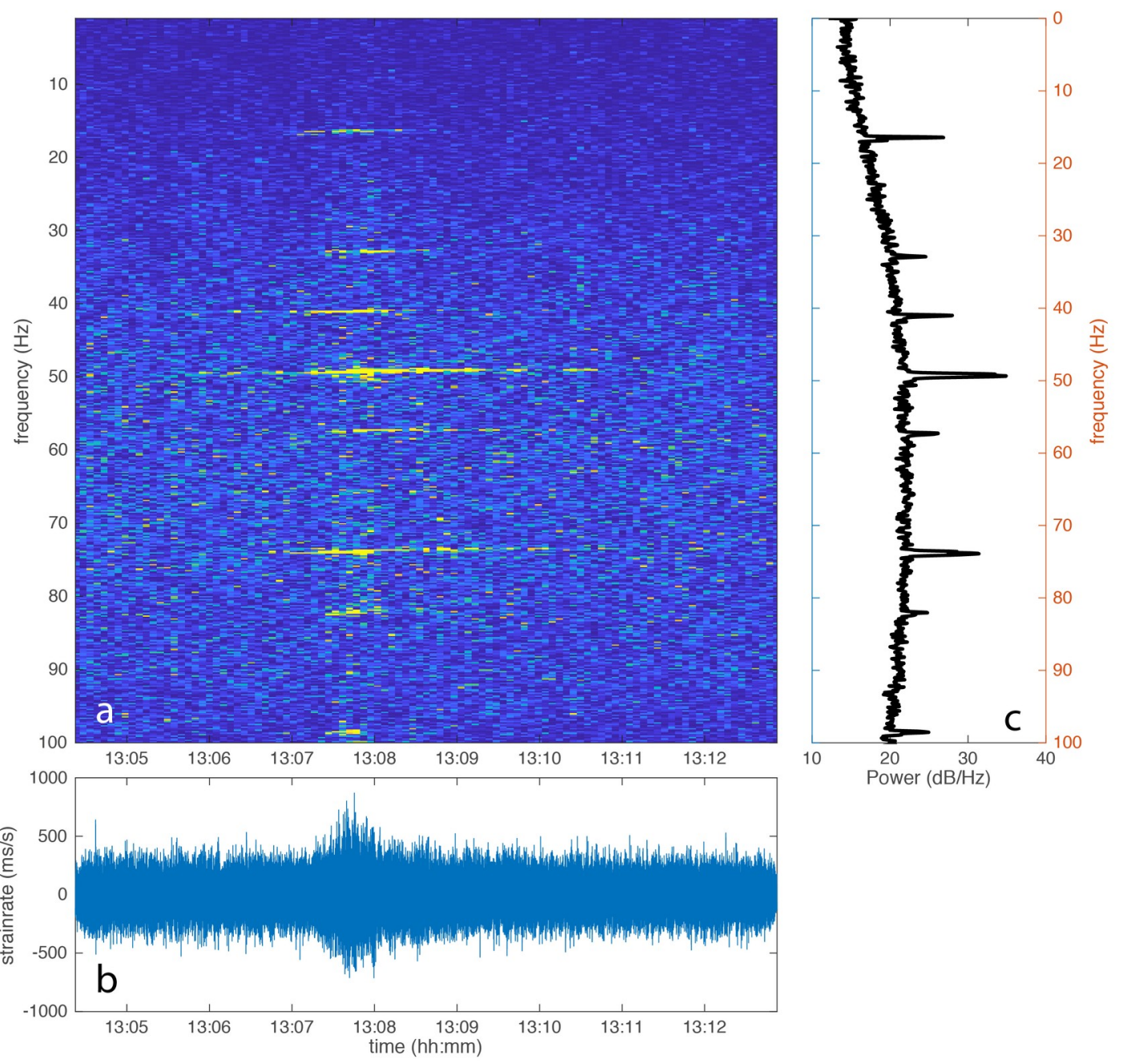

Figure 2 Strain-rate measured on the optical fiber at a distance of $5.9 \mathrm{~km}$ from the shore, while the tanker was passing above the cable at 5,8km and shown by the power spectrogram between 0 and $100 \mathrm{~Hz}(a)$, the corresponding time series (b) and the average power spectral density for 8 minutes time records (c). 


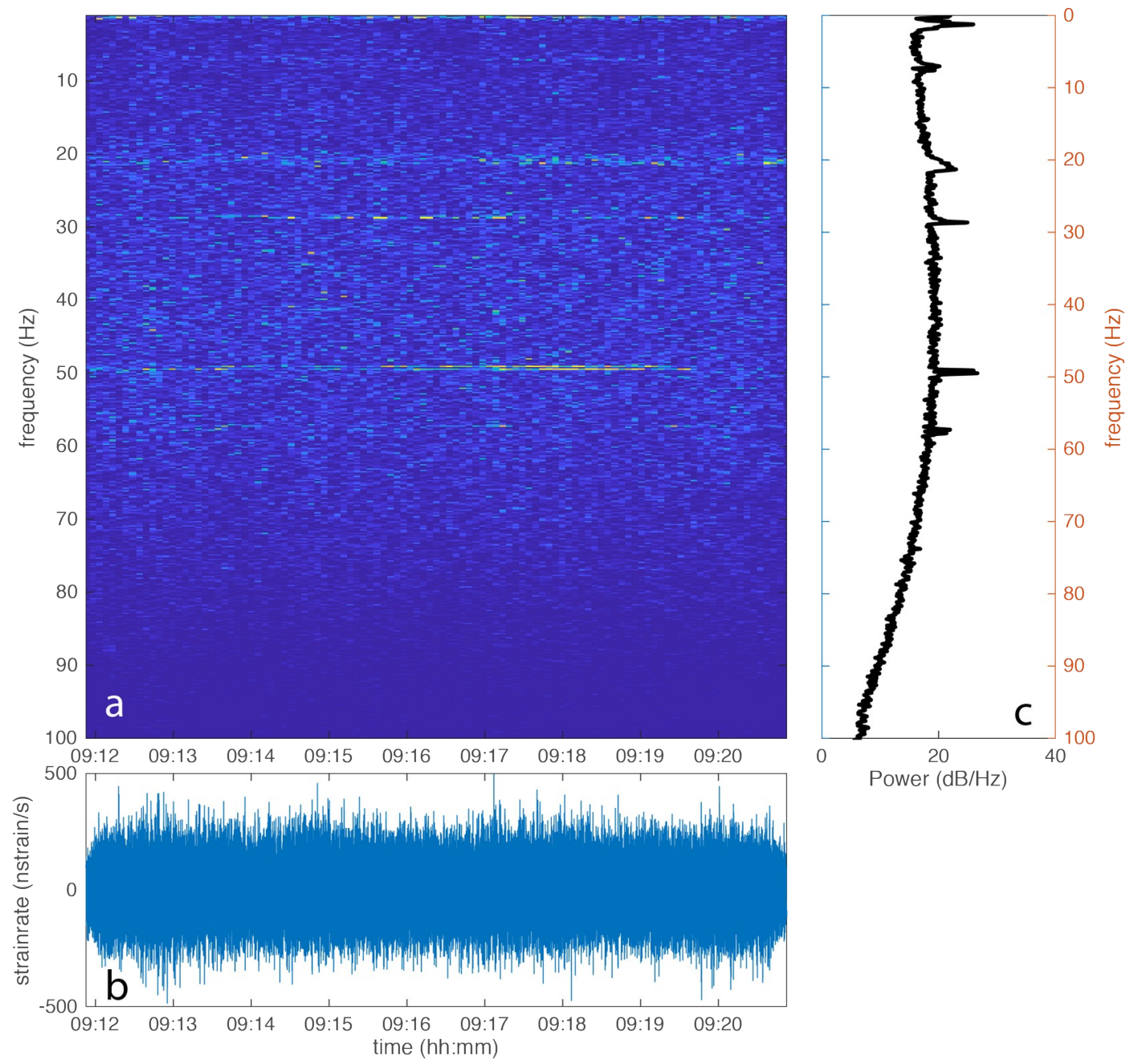

Figure 3 Strain-rate measured on the optical fiber at a distance of $20 \mathrm{~km}$ from the shore while the tanker was passing above the cable and shown by the power spectrogram between 0 and $100 \mathrm{~Hz}(\mathrm{a})$, the corresponding time series (b) and the average power spectral density for 9 minutes time $\operatorname{records}(c)$. 
(a)

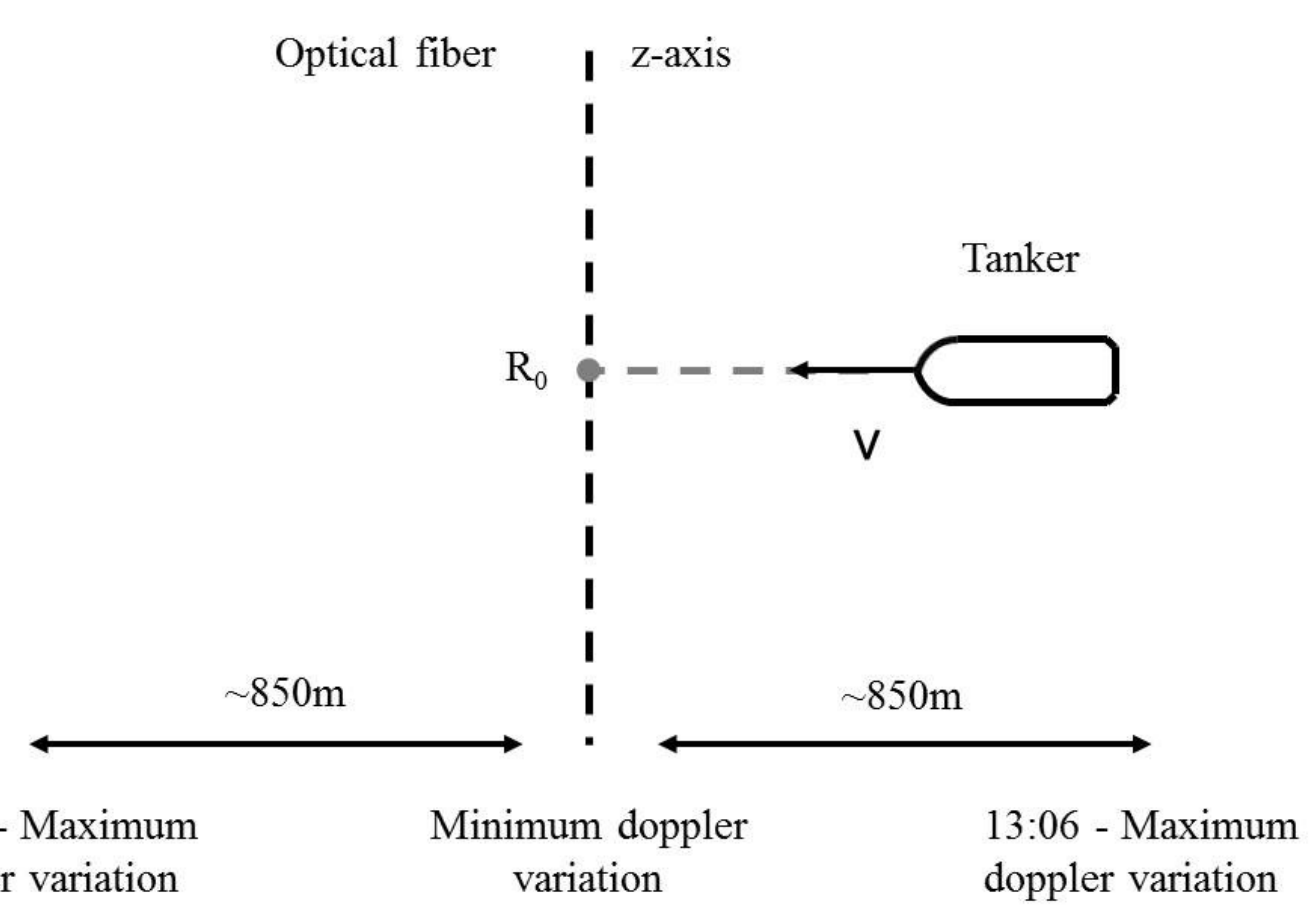

(b)

13:11 - Maximum doppler variation variation
- Source

- Receiver

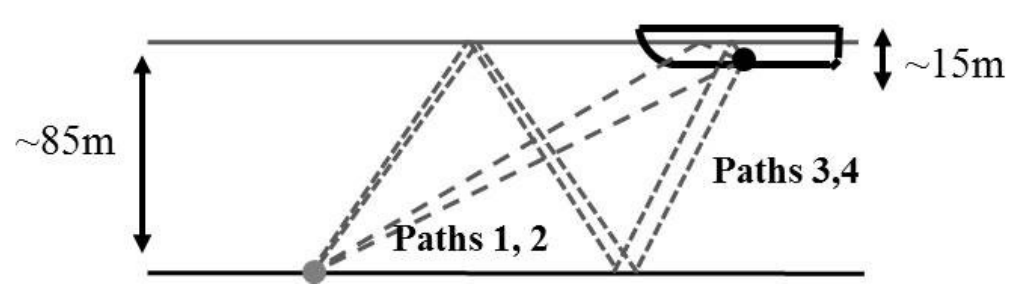

Figure 4 Ship displacement (a) top view (b) side view

By computing short Fourier transform every 4 seconds for each receiver in the vicinity of the ship, we monitor in space and time the intensity of height narrow band signals produced by the ship as it travels above the fiber at $5.8 \mathrm{~km}$ from the coast (Figure 5). We observe that the distance range on which we detect the tanker signal changes as a function of the frequency. Both the signal to noise ratio and the attenuation of acoustics waves depend on the frequency and therefore control the distance over which we detect a signal. Another important feature is these ring-like high intensity, clearly visible at $49 \mathrm{~Hz}$ and related to the interference of acoustic waves reflected on the surface and on the sea bottom (see Section IV). At 17Hz the ring shape are not visible because the wavelength at this frequency equals the water layer 
thickness and is control by a modal propagation. In addition to the noise emitted by the tanker, we observed other narrow band energy at a frequency higher than $100 \mathrm{~Hz}$ more likely related to the DAS self-noise. For instance at $137 \mathrm{~Hz}$, the intensity in time and space indicates that this noise randomly changes over time and space. The acoustic noise floor is different from the spectrogram shown in Figure 2 because we applied a median filter to better map coherent changes in the intensity.

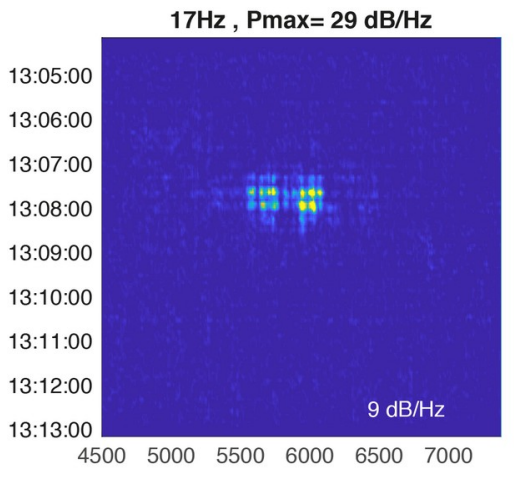

$49 \mathrm{~Hz}, \mathrm{Pmax}=47 \mathrm{~dB} / \mathrm{Hz}$

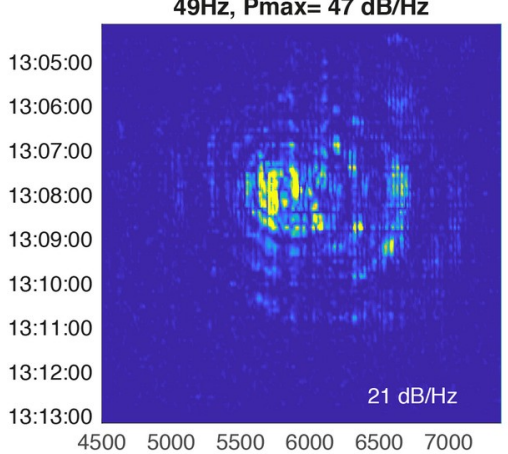

$82 \mathrm{~Hz}, \mathrm{Pmax}=34 \mathrm{~dB} / \mathrm{Hz}$

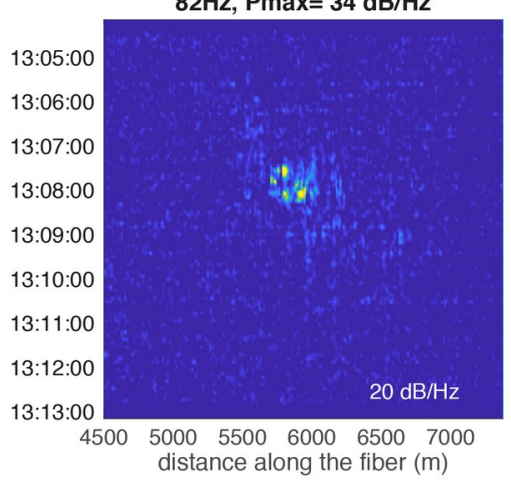

$33 \mathrm{~Hz}, \mathrm{Pmax}=33 \mathrm{~dB} / \mathrm{Hz}$

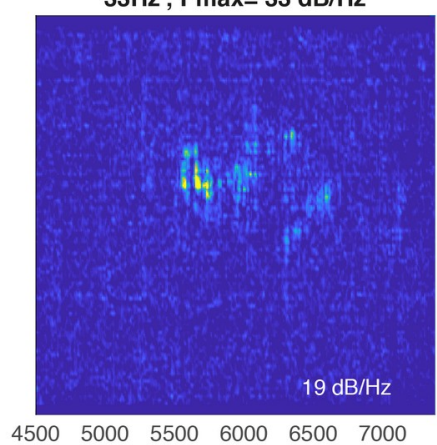

$57 \mathrm{~Hz}, \mathrm{Pmax}=37 \mathrm{~dB} / \mathrm{Hz}$

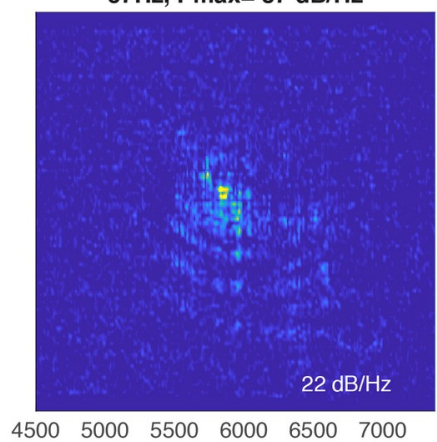

$98 \mathrm{~Hz}, \mathrm{Pmax}=30 \mathrm{~dB} / \mathrm{Hz}$

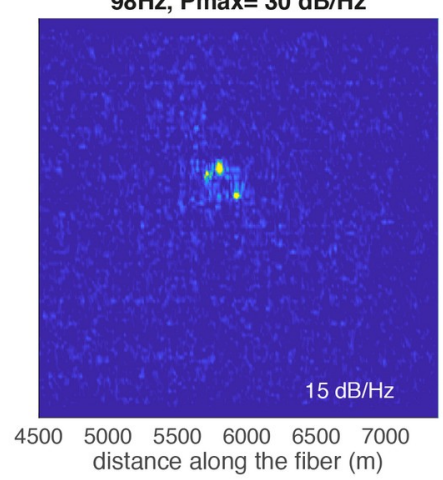

$41 \mathrm{~Hz}, \mathrm{Pmax}=38 \mathrm{~dB} / \mathrm{Hz}$

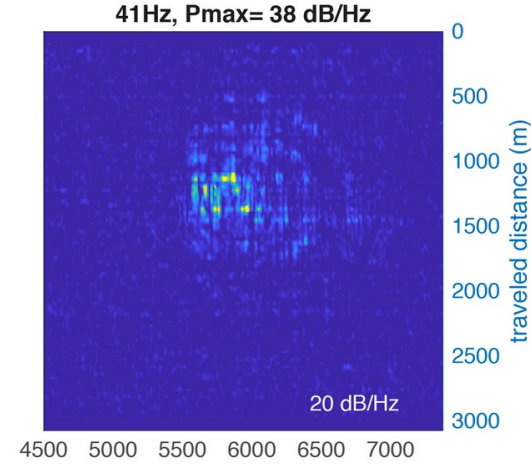

$73 \mathrm{~Hz}, \mathrm{Pmax}=40 \mathrm{~dB} / \mathrm{Hz}$

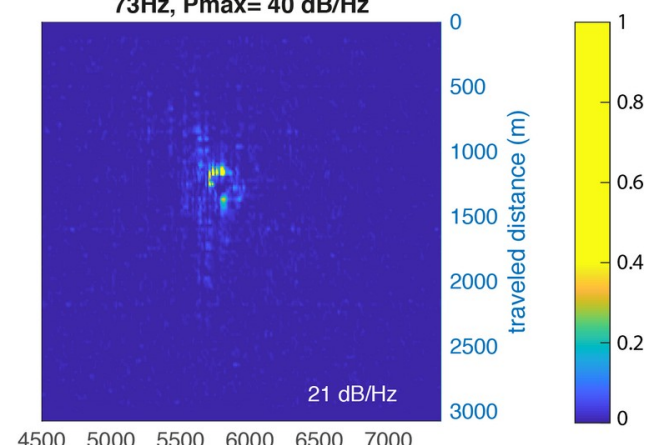

$137 \mathrm{~Hz}, \mathrm{Pmax}=8 \mathrm{~dB} / \mathrm{Hz}$

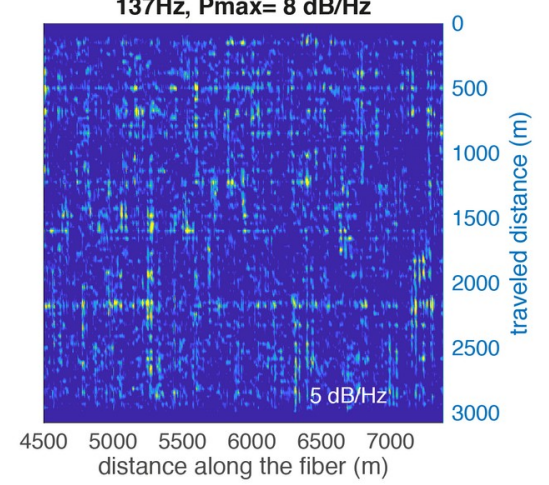

Figure 5 Acoustic noise intensity at individual frequencies in time and space along the optical fiber.

The traveled distance of the boat estimated from its velocity of 11 knot and the time are indicated on the right and left side of the figures respectively. In each figures the central frequency of a $1 \mathrm{~Hz}$ narrow band is indicated in the title, as well as the maximum intensity. The intensity of the noise 
recorded away from the tanker between 7000 and $7500 m$ fiber section between 13:12 and 13:13 is shown in white on the bottom right hand corner of each figures.

A greater depth, we estimated in space and time the intensity of some narrow band signals produced by the ship (Figure 6). Signal to noise ratio is significantly reduced compare to the intensity measured when the boat travels in shallow water. Because of the bathymetry and hence, a more complex coupling of the fiber with the ground, intensity pattern changes and it is less obvious to track the precise position of the tanker from these intensity maps. However, a higher intensity between 9:15 and 9:17 and between 20 and $21 \mathrm{~km}$, common in the different frequency bands, indicates a position of the boat close to the fiber and coherent to what is known from AIS.
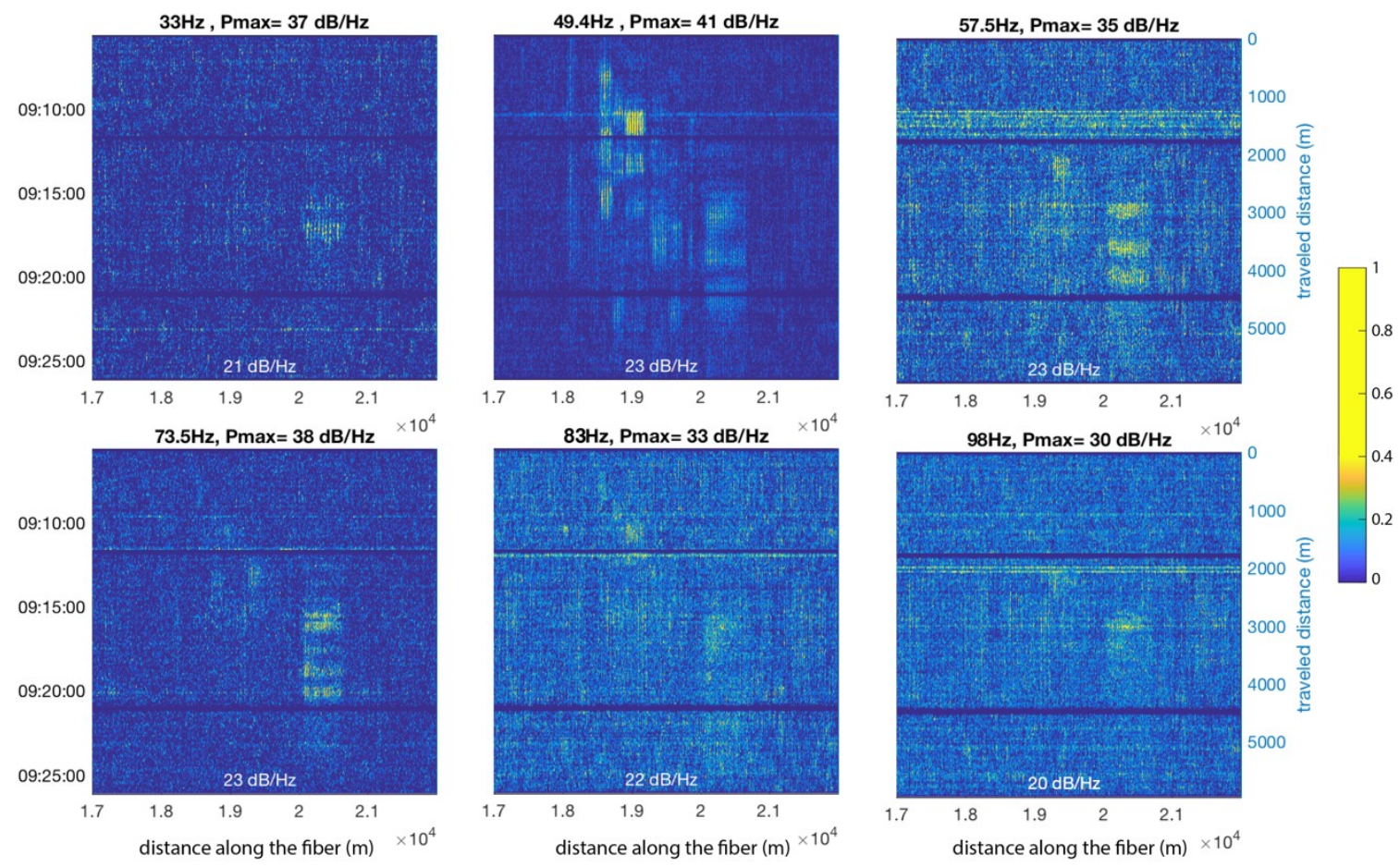

Figure 6 Acoustic noise intensity at individual frequencies in time and space along the optical fiber.

The traveled distance of the boat estimated from its velocity of 7,8 knot and the time are indicated on the right and left side of the figures respectively. In each figures the central frequency of a $1 \mathrm{~Hz}$ narrow band is indicated in the title, as well as the maximum intensity. The intensity of the noise 
recorded away from the tanker between 21 and 22km fiber section between 09:24 and 09:25 is shown in white on the bottom right hand corner of each figures.

\section{Modeling of the ship noise intensity on the optical fiber cable.}

In the following we model the intensity from analytical acoustics rays propagation and from the conversion from acoustic wave to longitudinal strain of the fiber, and its proper response related to the gauge length.

These acoustic waves produce an elongation of the fiber, therefore a strain in the axis of the fiber $x$ that can be written as (Bakku 2015):

$$
\epsilon_{x x}=\frac{-A_{0}}{\alpha} \cos ^{2} \delta e^{i(k \cdot r-\omega t)}
$$

with $A_{0}$ an amplitude factor, $\alpha$ the acoustic wave velocity, $\delta$ the angle with the $x$ axis, $k$ the wavenumber vector of the acoustic wave with $\vec{r}$ the vector between the source and the receiver, $\omega$ the pulsation and $t$ the time. The DAS measures average strain rate over the gauge length L (Bakku 2015) and its response to a strain rate leads to

$$
\epsilon_{D A S}=\epsilon_{x x} \operatorname{sinc}\left(k_{z} L / 2\right)
$$

The is equivalent to estimate the difference in velocities on the $x$ axis component of two geophones separated by a distance equals to the gauge length (Mateeva et al 2014).

Considering a source at $15 \mathrm{~m}$ depth, sixteen paths acoustic waves emitted by a tanker are considered in the model. Path 1 goes from the source at around $15 \mathrm{~m}$ depth directly to each receiver. Path 2 has more or less the same way but hit the surface first. Both path are represented in dashed lines Figure $4 \mathrm{~b}$. Other paths can be deduced by adding one, two or more bottom-surface reflection sequence to path 1 and 2. For example, paths 3 and 4 are represented in dotted lines on Figure 4b. 
The reflection coefficient depends on the incident angle - the Fresnel coefficient is computed and applied for each rebound - and on the nature of the soil, mainly composed by shales (Mascle 1971). Then, the sinc function computed at equation (3) and the attenuation by the square cosinus of the bearing have been taken into account.

The intensity map have been simulated over 4 minutes of record for the 2,4 , and 8 first paths at $49.4 \mathrm{~Hz}$ (Figure 7a-c). Figure 7a, we observe symmetrical shape with intensity reaching zero for $\mathrm{k}_{\mathrm{z}}$ equals zero. It comes to the fact that the model takes into account the null response of the fiber in the broadside. In Figure 7a, only two lobes of high intensity from either size of $\mathrm{k}_{\mathrm{z}}$ equals zero arising from the direct path of the acoustic waves. Figure $7 \mathrm{~b}$, with 4 paths, we observe a kind of ring shape that are more obvious Figure $7 \mathrm{c}$ ( 8 paths). This allows to explain the ring shapes observed Figure 6 with real data. Due to the ship motion over the fiber, the multipath interferences are permanently varying and create ring shapes on the $49,4 \mathrm{~Hz}$ response.

The final shape of the 8-paths model is not exactly the same of the one recorded on the fiber (Figure 7d). Many reasons can explain this fact: varying coupling of the fiber, varying depth for the considered area, possible fiber curvature. Nevertheless, the ring-like shapes size and spacing are similar enough so that the signals recorded by the fiber appear to come from acoustic multipath interfering within the water channel. Underwater telecom cables therefore behave as seismometer recording at the same time elastic signals coming from the ground (e.g. Sladen et al. 2019) and from the water. 

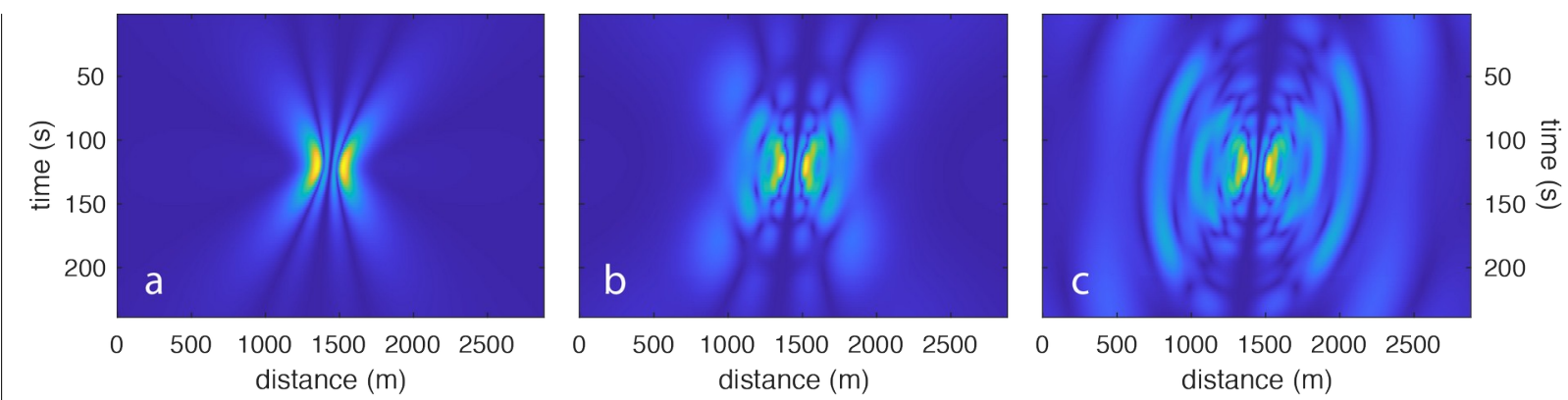

Figure 7 Signal intensity around $49.4 \mathrm{~Hz}$ for (a) 2 paths (b) 4 paths (c) 8 paths computed every 4 seconds for source crossing the fiber at constant velocity (11 $\mathrm{mph})$ and bearing (80 degrees). The received signal is computed at every time sample for a constant velocity of $2900 \mathrm{~m} / \mathrm{s}$ in the water layer. The reflection coefficient for each rays take into account the incidence angle and the nature of the seabed (shale). The model includes sixteen paths and takes into account the fiber response - Square cosinus of the bearing - and a spherical divergence for attenuation.

This section illustrates the DAS capability of registering acoustic waves in underwater environment. This comes in addition to other type of signals recorded by DAS system in under-water environment: seismological records from waves traveling from and through the earth, gravity waves and microseismic noise (Sladen et al. 2019) or seafloor excitation issued from ship trail (Rønnekleiv et al. 2019).

\section{Doppler estimation}

For a given receiver recording a single frequency $f_{0}$ emitted by a tanker moving at constant velocity $v$, the Doppler variation is given by

$$
\Delta f=f_{0} \cdot v \cdot \frac{\cos \theta}{c}
$$


where $c$ is the sound speed in the medium and $\theta$ the angle between the velocity vector $\mathbf{V}$ (Figure 4a) and the tanker-receiver direction. According to Section III, the ship starts to be detected around $49 \mathrm{~Hz}$ about $850 \mathrm{~m}$ away from the fiber. At this time and for the receiver R0, in the axis of the tanker (Figure 4a), we can estimate $\theta$ using $\tan (\theta) \approx \frac{85}{850}=0.1$ so that $\cos (\theta)=0.995 \approx 1.0$. For all the receivers in the vicinity of $R_{0}$, the apparent velocity roughly equals the tanker velocity and the Doppler variation tends to the maximum $\Delta f=f_{0} . v / c$. In the same way, when the $49 \mathrm{~Hz}$ record ends 5 minutes later, the distance of the fiber is about $850 \mathrm{~m}$ and the Doppler variation tends to its maximum value but with opposite sign (Figure 4a). Between those two events, considering that the tanker velocity vector is approximatively perpendicular to the fiber, the tanker will cross the fiber with a minimum Doppler variation equal or nearly equal to 0.0 for the portion of the cable close to R0.

We represent 8 minute-long strain-rate - including the 5 minutes $49 \mathrm{~Hz}$ detection described before - measured along $3 \mathrm{~km}$ and $5 \mathrm{~km}$ of fiber in the frequency-wavenumber domain when the tanker was passing at $5.8 \mathrm{~km}$ off shore (Figure $8 \mathrm{a}$ ). We observe two ellipses of energy centered around $49.2 \mathrm{~Hz}$ and $49.4 \mathrm{~Hz}$ for $k_{z}=0$. These frequencies are shifted by the doppler effect. The symmetries in time and space of the recorded scenario allows to consider that those two frequencies $-49.2 \mathrm{~Hz}$ and $49.4 \mathrm{~Hz}$ - are the one with minimum Doppler variations, i.e. two frequencies emitted by the tanker that can be recorded at the plumb line of the fiber. For each ellipse, we measure about $0.18 \mathrm{~Hz}$ Doppler shift from the center. Using equation 3 , with $f_{0}=49.4 \mathrm{~Hz}$, and $c=1500 \mathrm{~m} / \mathrm{s}$, it leads to a velocity of $5.46 \mathrm{~m} / \mathrm{s}$, which is very close to the $5.65 \mathrm{~m} / \mathrm{s}$ computed from AIS data.

When shifted toward the higher or lower frequencies - the tanker traveling toward or away from the fiber - the wave number increases or decreases accordingly keeping the wave 
velocity constant. At $2000 \mathrm{~m}$ depth at $20 \mathrm{~km}$ offshore (Figure $8 \mathrm{~b}$ ), the doppler shift is less pronounced indicating a slower velocity variation of the tanker seen by the DAS. Besides, acoustic waves have a more constant apparent wavelength on the fiber because the wavefronts are more planar, the source being at his closest point $2000 \mathrm{~m}$ above the fiber. Because the boat crosses the fiber with a nearly perpendicular route around the middle point of the selected portion of the fiber, the same energy is observed landward (positive wave number) and oceanward (negative wavenumber). The different coherent bands of energy with smaller frequency variation and smaller wave number are related to acoustics waves reflected in the water column.

The f-k representation of underwater DAS records allows discriminating rapidly environmental signal from the self-noise of the DAS and acquisition system. It could be used to track in a systematic way with continuous DAS records to detect acoustics signals. Here we test the feasibility of using the Doppler effect to estimate the velocity of the boat.

On the abyssal plain, at $2000 \mathrm{~m}$ depth, acoustic waves inside on the fiber with more planar wave front and the geometric attenuation is greater. The portions of the fiber will sense the acoustic wave are limited in space, which explain the narrow band in $k$. To better estimate the Doppler variation, we use a f-k representation of 1.3 minute-long strain-rate (Figure 9). Considering a maximum shift of $0,12 \mathrm{~Hz}$ at $49,05 \mathrm{~Hz}$, we measure a velocity of $3,7 \mathrm{~m} / \mathrm{s}-$ versus $4 \mathrm{~m} / \mathrm{s}$ estimated from AIS positions.

With a proper modeling of both the acoustic propagation in the water column and the doppler effect, taking into account the bathymetry and the fiber response, it will be possible to recover the position of the ship and its noise signature. 

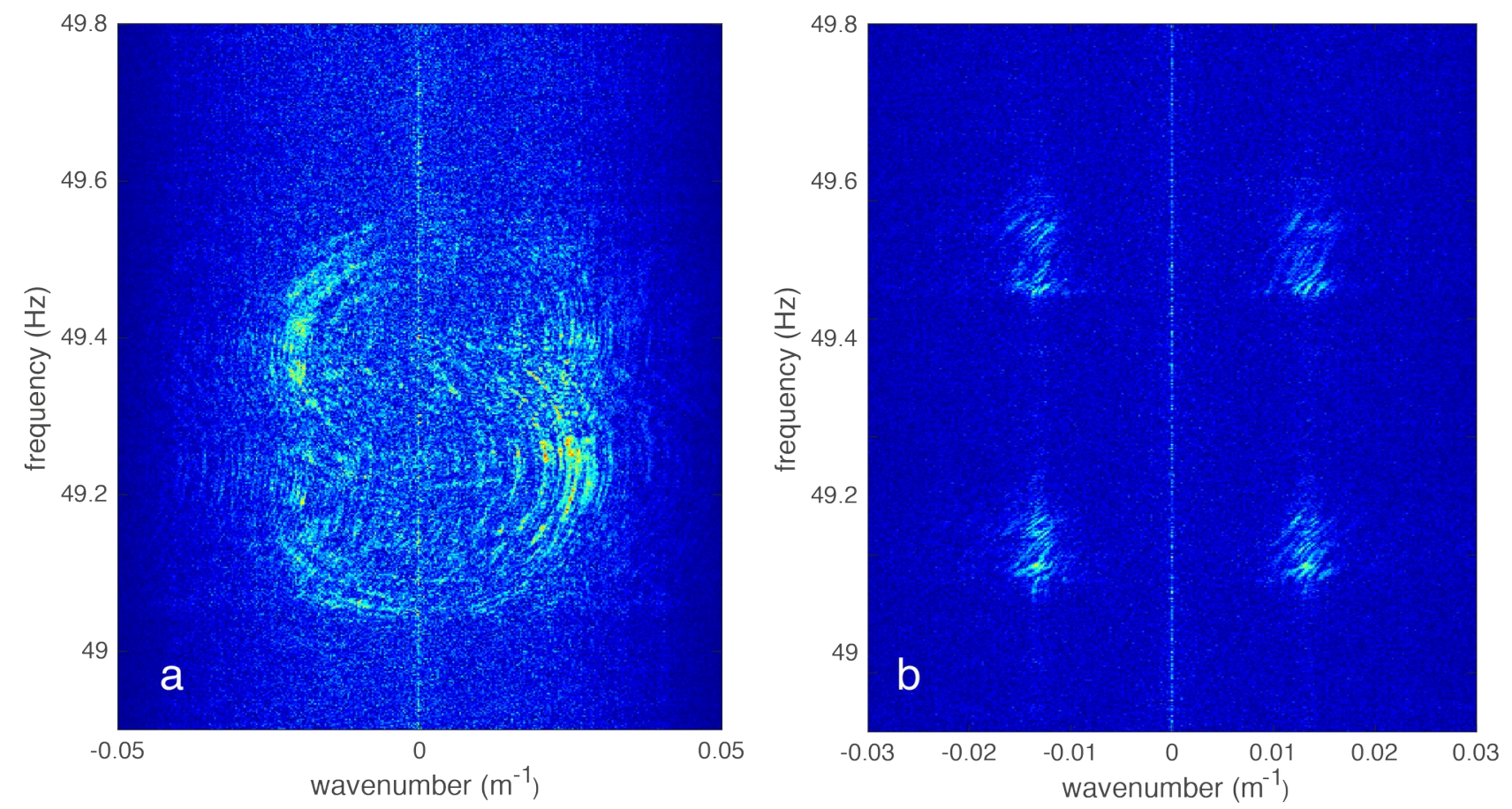

Figure 8 Frequency-wavenumber $(f-k)$ decomposition of 8 minute long strain-rate signal between 48.9 and $50.1 \mathrm{~Hz}$, for seaward $(k<0)$ and landward $(k>0)$ components and for the $4.5-7.5 \mathrm{~km}$ and the 17-22km sections of the fiber (a) and (a) respectively when the tanker passed over the cable
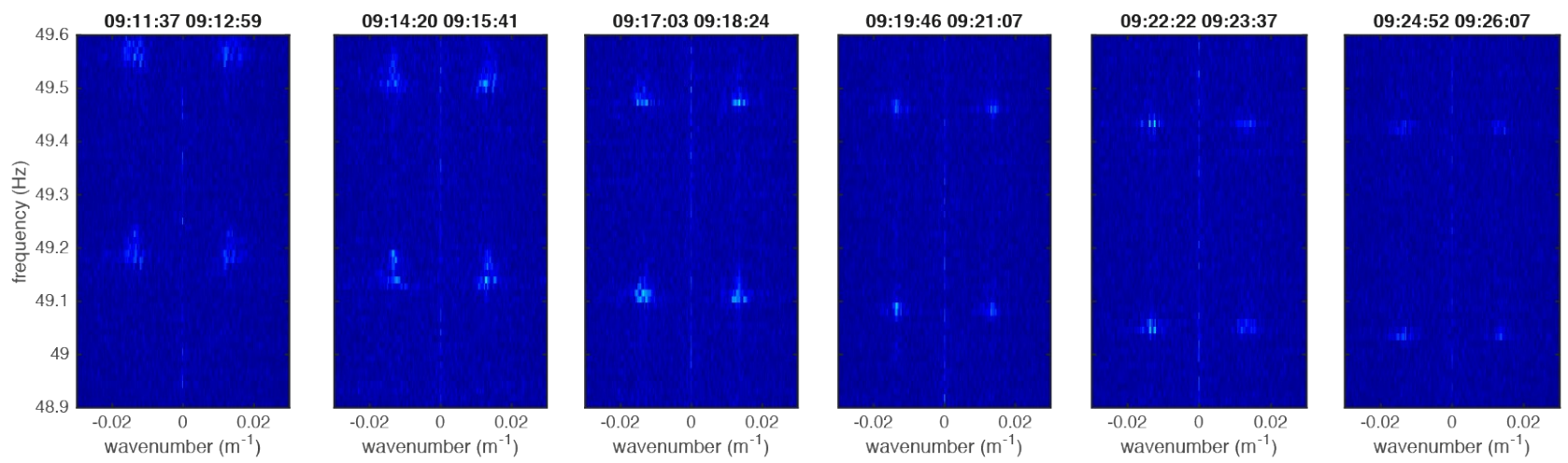

Tanker traveling toward the fiber

Tanker above the fiber

Tanker traveling away from the fiber

Figure 9 Frequency-wavenumber (f-k) decomposition of the strain-rate windowed on 1.3 minutes long signal between 48.9 and $49.6 \mathrm{~Hz}$, for seaward $(k<0)$ and landward $(k>0)$ components for the the $17-22 \mathrm{~km}$ sections of the fiber when the tanker passed $2000 \mathrm{~m}$ above the cable.

\section{Ship tracking}


To detect and track sources, sonar systems use various - and often multidimensional algorithms like beamforming, with narrow- or wide-band capabilities. DAS provides arrays of receivers that can be treated as an antenna, similar to sonar systems, to track maritime vessels.

For waves travelling through the earth, DAS signals has a shape driven by a square cosine for the strain produced by an acoustic waves (Bakku 2015) and also for the dynamic horizontal strain induced by the gravity waves (Appendix). This can be observed on a section of the fiber for which beamforming has been performed over the [0 - 100] Hz band for 25 seconds of ambient noise, assuming acoustic velocity of $1530 \mathrm{~m} / \mathrm{s}$ (Figure 10). The blue curve corresponds to a portion of the cable located at a depth between 100 and $200 \mathrm{~m}$. In red is a square cosine curve fitting the beamform and plotted to compare ambient noise with the theoretical omnidirectional case. The spurious pick at $90^{\circ}$ is related to coherent DAS selfnoise that has not been filtered at this step.

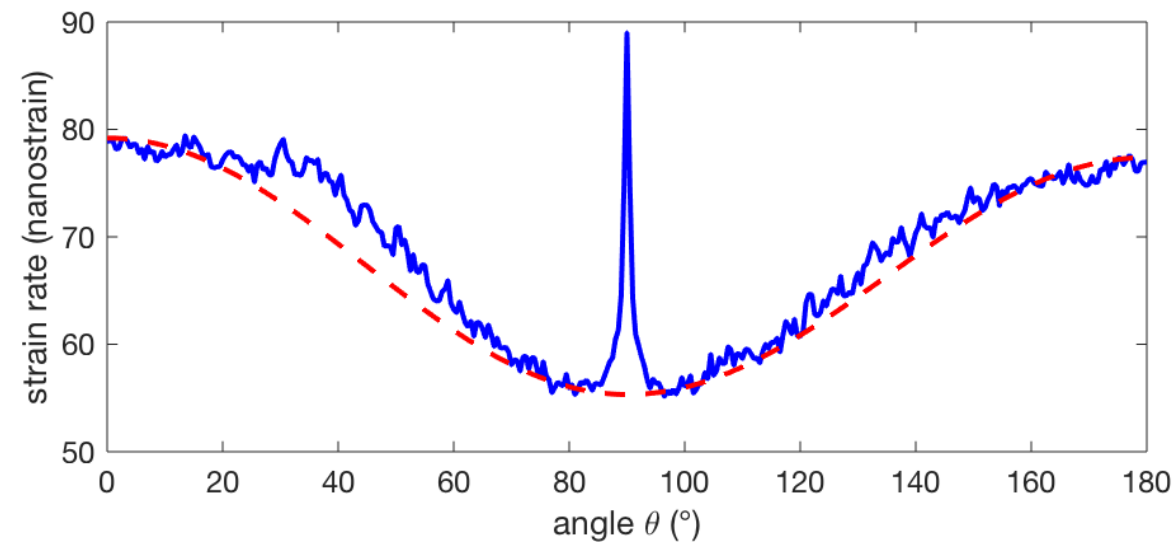

Figure 10 Beamforming output for (blue line) linear depth DAS-array between 4600-5912m off the coast, corresponding to a depth ranging from 100 to $200 \mathrm{~m}$, assuming a velocity of $1530 \mathrm{~m} / \mathrm{s}$. The dashed line shows the cos2 broadside sensitivity for acoustic waves.

From a linear section of the fiber between 5613 - 5869m we track the bearing of the tanker using the noise emitted in the $50 \mathrm{~Hz}$ frequency band. The center of the array is about $60 \mathrm{~m}$ from the plumb-line of the place where the ship cross the fiber in the direction of the coast. In this conditions, the ship is seen approximately in the broadside (i.e. 90 degrees bearing) when moving away from the fiber. It should deviate from this bearing until he crosses the fiber and then, come back to the broadside. The beamforming is computed in the time domain every $4 \mathrm{~s}$ and the result is given Figure 11. As expected, we observe the increasing remoteness from the broadside around $60 \mathrm{~s}$ up to $100 \mathrm{~s}$ an then the return to the broadside in a similar way. 
Considering a water column of $85 \mathrm{~m}$, we estimate that the boat crossed the fiber at a distance of $5821 \mathrm{~m}$ from the coast, for a real distance closer to $5800 \mathrm{~m}$ according to AIS positioning. The difference could be linked to depth approximation or AIS bias. It is more probably linked to the lack of precision for fiber positioning. Indeed, model used for the beamforming supposes a perfect alignment of the receiver what is not proven. By reducing the array length to $128 \mathrm{~m}$, the impact of a potential curvature of the fiber is reduced and the new founded position becomes $5806 \mathrm{~m}$ instead of $5800 \mathrm{~m}$.

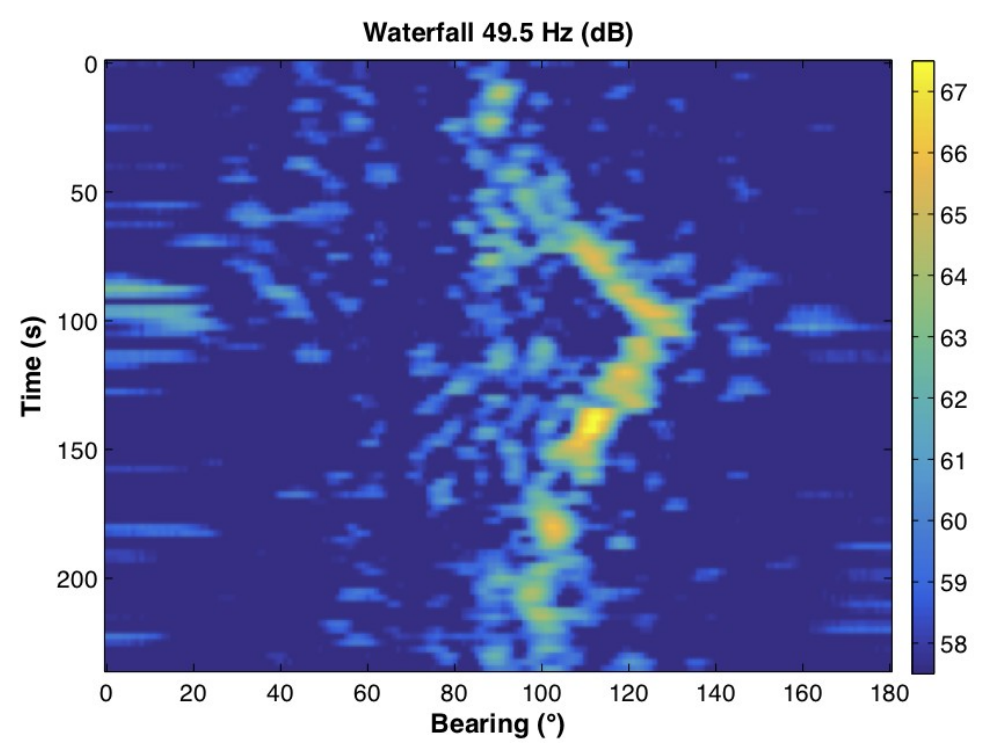

Figure 11 Beamforming performed over a linear antenna of $256 \mathrm{~m}$ length and centered at $5741 \mathrm{~m}$ from the fiber extremity. Focalization is around 550m. The beamforming is performed every 5 seconds using the recorded signal filtered in the [48 51]Hz band.

\section{Discussion}

Continuous and distributed monitoring of the acoustic noise over several tenth of kilometers can be achieved using acoustic sensing on telecom optical fiber. Acoustic waves traveling in the water layer interact directly with the fiber or penetrate the subsurface in case the cable is slightly buried in the sediments. These acoustic waves change locally in an infinitesimal way its length, leading to a longitudinal strain measurable by the DAS. 
We demonstrate the reliability of measuring accurately high frequency signal (up to $200 \mathrm{~Hz}$ ) on telecom cable which allow exploring other sources of acoustics signals in addition to seismic waves. This confirms the multidisciplinary potential for DAS on seafloor cables. We detect and track tanker up to $2000 \mathrm{~m}$ depth from the acoustic waves they produce. The appearance of high frequency narrow bands in the spectrum, over a given distance, and at a given time, and a Doppler shift of the frequency with time are the signature of the noise emitted by a ship and is therefore quite easy to identify from environmental and DAS seftnoise. Other features of the ship noise, such as the doppler shift of the moving source and the constant velocity of the acoustic waves in the water, help to track maritime vessels.

We model the principal features of the intensity from an analytical model. First order features like the ring shape and a decay of the energy right below the boat are well explained by the model and are related to acoustic reflection in the water column and the DAS broadside sensitivity. However, for a more accurate modeling of the intensity of the acoustic signal in time and space, a numerical models taking into account the sphericity of the acoustic wave field, the doppler effect and a non-constant water velocity profile should be computed. Modeling could also help estimating the coupling of the cable with the ground as it is important to estimate the response of the cable for different type of excitations - earthquakes, landslide, acoustic waves. Comparing observed and modeled noise intensity will probably help quantifying the degree of coupling of the fiber with the ground. Maritime vessels, which emits in the 1 to $200 \mathrm{~Hz}$ frequency band, can serve to estimate the high frequency response of the cable if we perform DAS and calibrated hydrophones acquisitions at the same time.

Beamforming takes advantage of the distributed sensing of the acoustic wave field measured on the fiber optic and allows a precise positioning of any maritime vessel both in time and space. The example given section VI shows the impact of fiber positioning. Additional calibration (using e.g. calibrated sources) to better estimates fiber response should also 
improve the result of the algorithm Future beamform should also integrate this azimuthal response of the fiber. The acoustic signature of vessels cruising in deeper waters needs to be further explored. The attenuation of the acoustic wave at depth strongly depends on the celerity profile of the sea and therefore could limit the range of depth on which we can detect high frequency signals.

\section{Conclusion}

We demonstrate the feasibility to record noise boats from the coast to the abyssal $(2000 \mathrm{~m})$ using DAS on standard underwater telecom cable, including multipath travelling in the water layer. Using f-k representation, it is possible to discriminate between moving sources and still sources or noise and to assess the speed of the sources by measuring the Doppler shift. Monitoring entropic noise at any depth in the sea can help the scientific community of precisely estimate its impact on marine life. Besides DAS telecom cable are very long underwater antenna - tenth of kilometers - and very dense - every meter - that can serve to track the position of maritime vessel in real time. If equipped with repeaters that allow the back scattered light to reach the DAS interrogator, worldwide telecom cables can serve as distributed environmental sensors measuring entropic noise and maritime traffic in addition to seismicity, gravity waves and microseisms.

\section{Appendix}

\section{Horizontal strain along the optical fiber cable produced by gravity waves}

We obtain the relationship between the strain along the fiber direction and the azimuth of the waves on the sea surface in two steps : first we get the expression of the velocity along the fiber (Gill, 1982), and we derive it to get the strain in this direction. 
The velocity potential $\Phi$ allows to describe the velocity $\mathbf{I}$ through the definition $\mathbf{I}=\nabla \Phi$. We consider the normalized $\mathbf{e}_{2}$ vector to be vertical going upward. Gravity waves traveling on the sea modeled as an inviscid and incompressible fluid can be described by the three following equations:

$$
\begin{gathered}
\nabla^{2} \Phi=0 \quad \text { for } z \leq 0 \\
\frac{\partial^{2} \Phi}{\partial t 2}+g \frac{\partial \Phi}{\partial z}-\frac{T}{\rho} \nabla^{2} \frac{\partial^{2} \Phi}{\partial t^{2}}=0 \quad \text { for } z=0 \\
\frac{\partial \Phi}{\partial z}=0 \quad \text { for } z=-h
\end{gathered}
$$

With $g$ been the gravitational acceleration, $h$ depth of the sea bed, $T$ the surface tension per unit length above the water surface, $\rho$ is the volumetric mass density of water. This model assumes for equation (1) that the product between the gravitational acceleration $\mathrm{g}$ and the depth $h$ of the sea bed is negligible compared with the square value of sound speed in water, which is well satisfied on Earth, and for equation (3) that the depth $h$ of the sea bed is constant.

We first consider the case of a monochromatic wave advancing along the direction $\mathbf{e}_{\mathrm{x}}$ that is to say a solution of the form $\Phi=f(z) e^{i k x-i \omega t}$ with a pulsation $\sigma$ and a wave number $\mathrm{k}$.

Hence, the solution satisfying equations (1), (2) and (3) is :

$\Phi=\frac{-i g A}{\omega}\left(1+\frac{T k^{2}}{g \rho}\right) \frac{\cosh (k(z+h))}{\cosh (k h)} e^{i(k x-\omega t)}$,

with A the surface wave amplitude.

This expression can easily be generalized to the case of a wave travelling in some direction defined by the normalized vector $\mathbf{e}_{\mathbf{w}}$ :

$\Phi=\frac{-i g A}{\omega}\left(1+\frac{T k^{2}}{g \rho}\right) \frac{\cosh (k(z+h))}{\cosh (k h)} e^{i\left(\mathbf{k}_{w} \mathbf{r}-\omega t\right)}$

with $\mathbf{k}_{w}=k \mathbf{e}_{w}$ and $\mathbf{r}=x \mathbf{e}_{x}+y \mathbf{e}_{y}+z \mathbf{e}_{z}$

We deduce the horizontal velocity from de spatial derivation of the potential along the direction $\mathbf{E}_{\mathbf{y}}$ of the fiber :

$\mathbf{u}_{x}=\nabla \Phi \cdot \mathbf{e}_{x}=i \mathbf{k}_{w} \cdot \mathbf{e}_{x} \Phi$

We then obtain the expression of the strain $\epsilon_{x y}$ of the water along the fiber : 
$\epsilon_{r x}=-\left(\mathbf{k}_{w} \cdot \mathbf{e}_{r}\right)^{2} \Phi$ that is to say $\epsilon_{r x}=-(\cos \delta)^{2} \Phi$ considering an azimuthal angle $\delta$ between the horizontal fiber and the surface wave direction.

\section{References}

Ajo-Franklin, J. B., Dou, S., Lindsey, N. J., Monga, I., Tracy, C., Robertson, M., ... \& Li, X. (2019). Distributed acoustic sensing using dark fiber for near-surface characterization and broadband seismic event detection. Scientific reports, 9(1), 1-14.

Bakku, S. K. (2015). Fracture characterization from seismic measurements in a borehole (Doctoral dissertation, Massachusetts Institute of Technology).

Coyle,P. KM3NeT Collaboration, KM3NeT-ORCA: Oscillation Research with Cosmics in the Abyss. J. Phys. Conf. Ser. 888 , 012024 (2017).

Daley, T. M., Freifeld, B. M., Ajo-Franklin, J., Dou, S., Pevzner, R., Shulakova, V., ... Lueth, S. (2013). Field testing of fiber-optic distributed acoustic sensing (DAS) for subsurface seismic monitoring. The Leading Edge, 32, 936-942.

Dou, S., Lindsey, N. J., Wagner, A., Daley, T. M., Freifeld, B. M., Robertson, M., ... AjoFranklin, J. B. (2017). Distributed acoustic sensing for seismic monitoring of the near surface: A traffic-noise interferometry case study. Scientific Reports, 7(1), 11620.

Fournier. G., 2009. Hydroacoustique et bruit des navires, Techniques de l'ingénieur.

Gill, A. E. (2016). Atmosphere-ocean dynamics. Elsevier. 
Gray, L. M., \& Greeley, D. S. (1980). Source level model for propeller blade rate radiation for the world's merchant fleet. the Journal of the Acoustical Society of America, 67(2), 516522.

Jousset, P., Reinsch, T., Ryberg, T., Blanck, H., Clarke, A., Aghayev, R., ... \& Krawczyk, C. M. (2018). Dynamic strain determination using fiber-optic cables allows imaging of seismological and structural features. Nature communications, 9(1), 1-11.

Lindsey N. J., Martin, E.R., Dreger D.S., Freifeld B., Cole S., James S.R., Biondi B.L. and Jonathan B. Ajo-Franklin, J.B. (2017) Fiber-Optic Network Observations of Earthquake Wavefields. Geophysical Research Letters. 11792-11799

Mascle, J. (1971) Géologie sous-marine du canyon de Toulon, Cahiers océanographiques.

Mateeva, A., Lopez, J., Mestayer, J., Wills, P., Cox, B., Kiyashchenko, D., ... Grandi, S. (2013). Distributed acoustic sensing for reservoir monitoring with VSP. The Leading Edge, $32,1278-1283$.

Mateeva, A., Lopez, J., Potters, H., Mestayer, J., Cox, B., Kiyashchenko, D., ... Detomo, R. (2014). Distributed acoustic sensing for reservoir monitoring with vertical seismic profiling. Geophysical Prospecting, 62(4), 679-692.

Merchant, N. D. 2019. Underwater noise abatement: Economic factors and policy options. Environmental science \& policy, 92, 116-123. 
Miller, D. E., Daley, T. M., White, D., Freifeld, B. M., Robertson, M., Cocker, J., \& Craven, M. (2016). Simultaneous acquisition of distributed acoustic sensing VSP with multi-mode and single-mode fiber optic cables and 3-component geophones at the Aquistore $\mathrm{CO}_{2}$ storage site. CSEG Recorder: June 2016, 28.

Pillon, D. 2016. Introduction à la détection sous-marine passive, Techniques de l'ingénieur.

Rønnekleiv, E., Brenne, J. K., Waagaard, O. H., Moussakhani B. (2019) Distributed acoustic sensing for submarine cable protection. Suboptic2019, 8-11 April 2019 - New Orleans Marriott - 555 Canal Street, New Orleans, Louisiana 70130 USA.

Sladen, A., Rivet, D., Ampuero, J. P., De Barros, L., Hello, Y., Calbris, G., \& Lamare, P. (2019). Distributed sensing of earthquakes and ocean-solid Earth interactions on seafloor telecom cables. Nature Communications, 10(1), 1-8.

Williams, E., Fernandez-Ruiz, M. R., Magalhaes, R., Vanthillo, R., Zhan, Z., GonzalezHerraez, M., \& Martins, H. F. (2019, May 30). Teleseisms and Microseisms on an OceanBottom Distributed Acoustic Sensing Array. https://doi.org/10.31223/osf.io/kg7q4

Williams, R., Wright, A.J., Ashe, E., Blight, L.K., Bruintjes, R., Canessa, R., Clark, C.W.,Cullis-Suzuki, S., Dakin, D.T., Erbe, C., Hammond, P.S., Merchant, N.D., O’Hara, P.D.,Purser, J., Radford, A.N., Simpson, S.D., Thomas, L., Wale, M.A., 2015. Impacts of anthropogenic noise on marine life: publication patterns, new discoveries, and future 
directions in research and management. Ocean Coast. Manag. 115, 17-24. https://doi.org/10.1016/j.ocecoaman.2015.05.021. 